Hydrol. Earth Syst. Sci., 17, 2449-2458, 2013

www.hydrol-earth-syst-sci.net/17/2449/2013/

doi:10.5194/hess-17-2449-2013

(C) Author(s) 2013. CC Attribution 3.0 License.

\title{
Rainfall statistics changes in Sicily
}

\author{
E. Arnone ${ }^{1}$, D. Pumo ${ }^{1}$, F. Viola ${ }^{1,2}$, L. V. Noto ${ }^{1,2}$, and G. La Loggia ${ }^{1,2}$ \\ ${ }^{1}$ Dipartimento di Ingegneria Civile, Ambientale, Aerospaziale, dei Materiali, Palermo, Italy \\ ${ }^{2}$ Consorzio Interuniversitario Nazionale per la Fisica delle Atmosfere e delle Idrosfere (CINFAI), Palermo, Italy
}

Correspondence to: E. Arnone (elisa.arnone@unipa.it)

Received: 3 January 2013 - Published in Hydrol. Earth Syst. Sci. Discuss.: 22 February 2013

Revised: 20 May 2013 - Accepted: 2 June 2013 - Published: 4 July 2013

\begin{abstract}
Changes in rainfall characteristics are one of the most relevant signs of current climate alterations. Many studies have demonstrated an increase in rainfall intensity and a reduction of frequency in several areas of the world, including Mediterranean areas. Rainfall characteristics may be crucial for vegetation patterns formation and evolution in Mediterranean ecosystems, with important implications, for example, in vegetation water stress or coexistence and competition dynamics. At the same time, characteristics of extreme rainfall events are fundamental for the estimation of flood peaks and quantiles that can be used in many hydrological applications, such as design of the most common hydraulic structures, or planning and management of floodprone areas.
\end{abstract}

In the past, Sicily has been screened for several signals of possible climate change. Annual, seasonal and monthly rainfall data in the entire Sicilian region have been analyzed, showing a global reduction of total annual rainfall. Moreover, annual maximum rainfall series for different durations have been rarely analyzed in order to detect the presence of trends. Results indicated that for short durations, historical series generally exhibit increasing trends, while for longer durations the trends are mainly negative.

Starting from these premises, the aim of this study is to investigate and quantify changes in rainfall statistics in Sicily, during the second half of the last century. Time series of about 60 stations over the region have been processed and screened by using the nonparametric Mann-Kendall test.

In particular, extreme events have been analyzed using annual maximum rainfall series at $1,3,6,12$ and $24 \mathrm{~h}$ duration, while daily rainfall properties have been analyzed in terms of frequency and intensity, also characterizing seasonal rainfall features. Results of extreme events analysis confirmed an increasing trend for rainfall of short durations, especially for
$1 \mathrm{~h}$ rainfall duration. Conversely, precipitation events of long durations have exhibited a decreased trend. Increase in shortduration precipitation has been observed especially in stations located along the coastline; however, no clear and welldefined spatial pattern has been outlined by the results. Outcomes of analysis for daily rainfall properties have showed that heavy-torrential precipitation events tend to be more frequent at regional scale, while light rainfall events exhibited a negative trend at some sites. Values of total annual precipitation events confirmed a significant negative trend, mainly due to the reduction during the winter season.

\section{Introduction}

The considerable impacts of climate change on our environment have led the scientific community to direct constant attention to the analysis of possible trends and their possible implications. Change in extreme events can directly or indirectly impact natural environments and human activities (Kunkel et al., 1999b), as well as human health and safety. Over the last decades, several studies on rainfall trends have been carried out throughout the world; such studies have investigated potential trends in different rainfall variables, such as total annual precipitation, mean daily intensity and annual maxima for fixed durations, as well as at different temporal scales, such as annual or seasonal.

Trenberth et al. (2007) provide a comprehensive view of such studies. In some areas, analyses of daily series of the last few decades have shown a positive trend in daily precipitation intensity and a tendency toward higher frequencies of heavy and extreme rainfall (Houghton et al., 1996). The areas where precipitation events have shown the most relevant positive trends are the US (Kunkel et al., 1999a; Trenberth 
et al., 2007; Villarini et al., 2011), eastern and northeastern Australia (Plummer et al., 1999), South Africa (Mason et al., 1999), the UK (Osborn et al., 2000) and northern and central Italy (Brunetti et al., 2000, 2001). Most of the areas with a positive trend in rainfall intensity have shown an increase in total precipitation as well (Groisman et al., 1999). However, in some areas, such as in northern Italy, an increase in heavy precipitation has been detected simultaneously with a decreasing trend in total precipitation (Brunetti et al., 2001; Alpert et al., 2002). Besides the increasing trend observed in rainfall intensity, global observations indicate that the overall percentage of the Earth's surface is affected by either drought or excessive wetness has increased (Dai et al., 1998).

Analyses on extreme rainfall events have been carried out by Burn et al. (2011), Adamowski et al. (2010) and De Toffol et al. (2009). Burn et al. (2011) analyzed hourly rainfall data for durations of 1, 2, 6, 12 and $24 \mathrm{~h}$ in British Columbia; their results have revealed generally increasing trends in extreme rainfall, especially for the summer season and for the short-duration rainfall events. With regard to urban catchment, Adamowski et al. (2010) analyzed linear trends for different combinations of durations and frequencies of annual short-duration extreme rainfall by considering time series from 15 meteorological stations in Ontario, Canada, and short-duration rainfall events of 5, 10, 15 and $30 \mathrm{~min}$ and $1 \mathrm{~h}$. For all the durations they obtained significant increasing trends. De Toffol et al. (2009) considered the intensities over 15 and $30 \mathrm{~min}$ and $1,2,12$ and $24 \mathrm{~h}$ to investigate the changes in short-duration rainfall intensities in the Austrian Alpine region Tyrol relevant to urban drainage systems; they concluded that there is an increasing trend in the rainfall intensity for short durations, and there is a more significant increase in number of extreme rainfall events.

A number of studies are specifically addressed to the Mediterranean areas, given the peculiar climate of such areas. The Mediterranean region is affected by interactions between mid-latitude and tropical processes since it lies between the arid climate of North Africa and the temperate and rainy climate of central Europe. For these reasons, even relatively minor modifications of the general circulation can lead to substantial changes in the Mediterranean climate (Giorgi and Lionello, 2008). This makes the Mediterranean areas a potentially vulnerable region to climatic changes (Lionello et al., 2006; Ulbrich et al., 2006).

Alpert et al. (2002) conducted a coherent study of the full scale of daily rainfall categories over the Mediterranean in order to assess the paradoxical behavior characterized by an increase of extreme rainfall in spite of a decrease in the totals. The authors showed that the torrential rainfall in Italy exceeding $128 \mathrm{~mm} \mathrm{~d}^{-1}$ has increased by a factor of 4 percent during the period 1951-1995. In Spain, extreme categories (light: $0-4 \mathrm{~mm} \mathrm{~d}^{-1}$ and heavy/torrential: $64 \mathrm{~mm} \mathrm{~d}^{-1}$ and up) have experienced significant increase, different to those of Israel and Cyprus, where no significant trends were observed. It is clear how the consequent redistribution of the daily rainfall categories - torrential/heavy against moderate/light intensities - is of crucial interest, particularly in the semiarid subtropical regions, with regard to water management, soil erosion and flash flood impacts.

In Italy, Brunetti et al. (2001) analyzed 67 sites of daily precipitation records over the 1951-1996 period. They investigated seasonal and yearly total precipitation, number of wet days and precipitation intensity, and they studied the trends both from the single-station records as well as other different areas by using averaged series. The results showed that the trend for the number of wet days in the year is significantly negative throughout Italy, particularly stronger in the north than in the south, especially in the winter. They also showed a tendency toward an increase in precipitation intensity, which is globally less strong and significant than the decrease in the number of wet days. In northern Italy, such an increase is mainly owing to a strong increase in the heaviest events, while in central-southern Italy, it depends on a larger part of the distribution of the amount of wet days.

Sicily has been screened for several climate change signals as well: Aronica et al. (2002) analyzed the series of maximum intensity for fixed duration $(1,3,6,12,24 \mathrm{~h})$ and annual daily maxima in the Palermo urban area by estimating the maximum rainfall depth corresponding to a fixed return period using the EV1 distributions. They observed a global reduction of rainfall intensities, in disagreement with the results obtained by other authors. Annual maximum rainfall series of different durations were also screened by Bonaccorso et al. ( 2005), who assessed the presence of linear and nonlinear trends. They analyzed 16 series from rain gauge stations mostly placed in the eastern Sicily, and the results indicated that for short durations, historical series generally exhibit increasing trends, while for longer durations the trends are mainly negative. Cannarozzo et al. (2006) analyzed annual, seasonal and monthly rainfall data in the entire Sicilian region, showing a global reduction of total annual rainfall, which is mainly due to the winter reduction.

Previous studies have demonstrated a clear reduction in annual rainfall, mainly concentrated during the winter, which is in agreement with tendencies observed in southern Mediterranean areas. However, there is a lack of knowledge on how and if rainfall properties have changed during the last century. Although changes in rainfall extremes may have tremendous implications on engineering design and flood risk assessment, a comprehensive analysis on these changes is missing in the scientific literature. Similarly, changes in daily rainfall intensity and frequency may have large impacts on ecosystems, as investigated by Pumo et al. (2010); however analyses on changes in rainfall properties are missing as well.

This study aims to provide a comprehensive investigation for understanding how extreme events, daily rainfall and rainfall properties in Sicily have changed in the last century.

Particularly, the study analyzes the annual maximum rainfall for fixed duration $(1,3,6,12$ and $24 \mathrm{~h})$ and the daily 
rainfall series recorded from 1956 to 2005 at about 60 stations. The daily rainfall events are analyzed by classifying the events into different intensity-based rainfall categories, namely light, light-moderate, moderate-heavy, heavy, heavy-torrential and torrential precipitation. The number of occurrences and the contribution of each class to the total precipitation are analyzed for assessing signals of trend. Changes in frequency, at both the annual and the seasonal scale, are investigated by analyzing the interarrival times between subsequent events. The presence of any significant trend has been detected using the nonparametric Mann-Kendall test.

The structure of the manuscript is as follows: Sect. 2 introduces the methodology and the dataset used in the analysis, providing a description of the adopted trend detection test, the regional dataset and the derived rainfall variables screened for the analysis; Sect. 3 reports the discussion of the results, concerning each analyzed variable. Finally, the relevant conclusions arising from this study are reported in Sect. 4.

\section{Methodology and dataset}

\subsection{Trend detection test}

The nonparametric Mann-Kendall test (Mann, 1945; Kendall, 1962) is used in this study to detect any potential trend in the analyzed time series. The test identifies the presence of a trend without making an assumption about the distribution properties, and as a result is less influenced by the presence of outliers than the parametric tests. The test statistic Kendall's $S$ (Kendall, 1962) is calculated as

$S=\sum_{i=1}^{n-1} \sum_{j=i+1}^{n} \operatorname{sign}\left(x_{j}-x_{i}\right)$,

where $x_{i}$ and $x_{j}$ are the data values at times $i$ and $j, n$ is the length of the dataset and

$\operatorname{sign}\left(x_{j}-x_{i}\right)=\left\{\begin{array}{cl}1 & \text { if }\left(x_{j}-x_{i}\right)>0 \\ 0 & \text { if }\left(x_{j}-x_{i}\right)=0 \\ -1 & \text { if }\left(x_{j}-x_{i}\right)<0,\end{array}\right.$

where $\operatorname{sign}(x)$ is an odd mathematical function that extracts the sign of the variable $x$.

Under the null hypothesis that there is no trend in the population, and thus $x_{i}$ are independent and randomly ordered, the statistic $S$ is approximately normally distributed when $n \geq 8$, with zero mean and variance as follows:

$\sigma^{2}=\frac{n(n-1)(2 n+5)}{18}$.

The standardized test statistic $Z_{S}$ is computed by

$Z_{S}= \begin{cases}\frac{S-1}{\sigma} & \text { if } S>0 \\ 0 & \text { if } S=0 \\ \frac{S+1}{\sigma} & \text { if } S<0\end{cases}$ and compared with a standard normal distribution at the required level of significance. If the significance level, $\alpha_{\text {sig }}$, is set equal to 0.05 , the null hypothesis is verified when $\left|Z_{s}\right|<1.96$. A positive value of $Z_{s}$ indicates an increasing trend and vice versa. Local significance levels ( $p$ values) for each trend test can be obtained from the fact that

$p=2\left[1-\Phi\left(\left|Z_{S}\right|\right)\right]$,

where $\Phi(\cdot)$ denotes the cumulative distribution function of a standard normal variate. The magnitude of trends is given by a nonparametric robust estimate determined by Hirsch et al. (1982):

$\beta=\operatorname{Median}\left(\frac{x_{j}-x_{l}}{j-l}\right) \quad \forall l<j$,

where $x_{l}$ is the $l$-th observation antecedent to the $j$-th observation $x_{j}$.

In order to verify the existence of any positive/negative serial correlation in the used time series, we analyzed the lag-1 autoregressive process, AR (1), of all the series, obtaining an autocorrelation coefficient close to zero. This result allowed us to apply the Mann-Kendall without processing a prewhitening procedure, which is required to eliminate any possible noise affecting the trend results (Yue and Wang, 2002).

\subsection{The regional dataset}

Sicily is the largest island in the Mediterranean Sea, and it extends over an area of approximately $25700 \mathrm{~km}^{2}$. The rainfall dataset has been selected from the regional database published by Osservatorio delle Acque - Agenzia Regionale per i Rifiuti e le Acque (OA-ARRA), which consists of annual maximum rainfalls for $1,3,6,12$ and $24 \mathrm{~h}$ duration, daily rainfall and annual maximum daily rainfall. Rainfall data were recorded at 365 rain gauges within the period 19292009. The sample size arising from the different stations varies from 9 to $63 \mathrm{yr}$ with a mean size of $28.5 \mathrm{yr}$. Location of rain gauges and the spatial distribution of the mean annual precipitation (Di Piazza et al., 2011) are shown in Fig. 1a.

A preliminary analysis has been made in order to identify the time window with the highest number of running rain gauge stations. Figure 1b, on the left, shows the observation matrix relative to the whole annual maximum rainfall dataset; black pixels denote running rain gauges, while gray pixels are used for the intermittently recording rain gauges. In order to identify the final dataset, two subsequent selections have been made on the initial dataset based on two criteria: first, a time window with at least 60 running rain gauge stations per year has been identified; secondly, from this selection, the stations that have recorded for less than $40 \mathrm{yr}$ have been removed. The resulting time window is shown in the left panel of Fig. $1 \mathrm{~b}$ by the two vertical black lines characterizing a $50 \mathrm{yr}$ period (1956-2005); the final subset is shown 

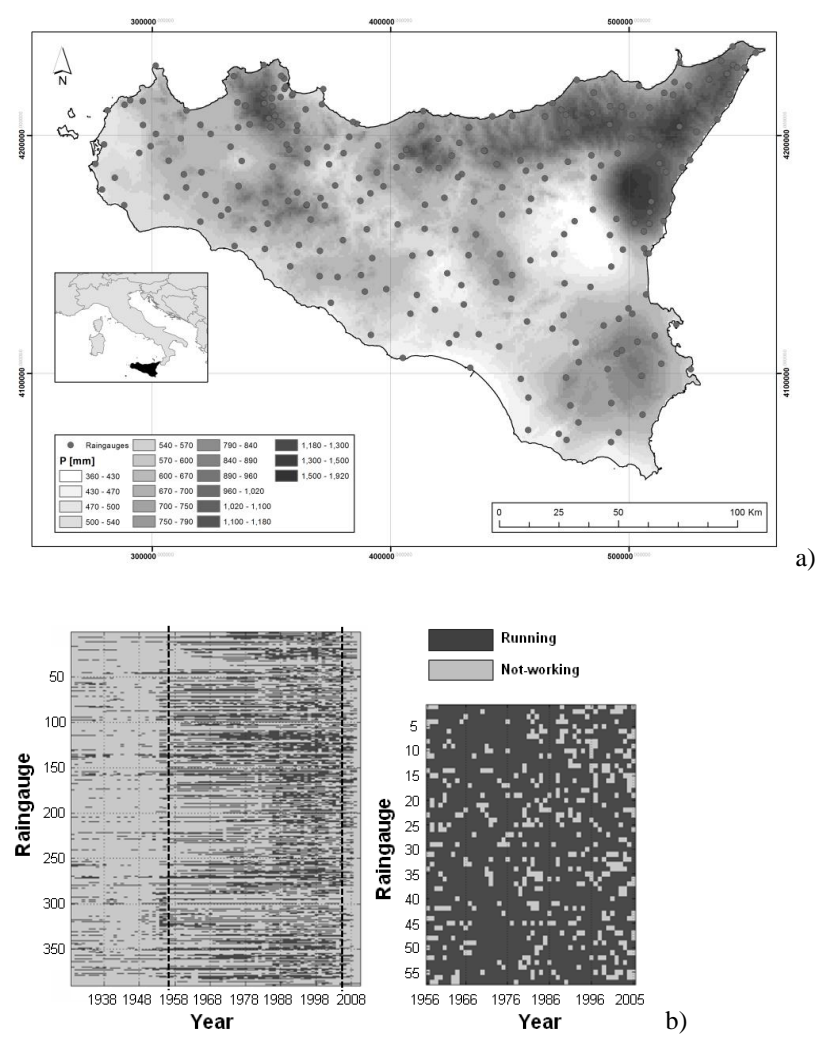

Fig. 1. Location of rain gauge stations over the region and spatial distribution of mean annual rainfall depth, from Di Piazza et al. (2011) (a). The running and the intermittently recording rain gauges over the entire period of observation (1929-2009) (b, on the left) and selected dataset, i.e., stations (57) and time of observation (1956-2005) (b, on the right). Data are from the regional database published by Osservatorio delle Acque - Agenzia Regionale per i Rifiuti e le Acque (OA-ARRA).

in the right panel of Fig. 1b, which counts 57 rain gauge stations distributed over the whole region, with an average sample size of $45.48 \mathrm{yr}$.

An overview of the rainfall series statistics is provided in Fig. 2, which shows, for each rain gauge station, the mean and the standard deviation values of the annual maximum rainfall time series for $1,3,6,12$ and $24 \mathrm{~h}$ duration and the total annual precipitation. In terms of annual precipitation, data show considerable variability, with mean values ranging from $400 \mathrm{~mm}$ to $1300 \mathrm{~mm}$. A less variant behavior is exhibited by the annual maximum series, where only the gauge station with ID $=52$ (located at Zafferana Etnea, eastern Sicily) shows mean values much higher than the others stations.

\subsection{Analyzed rainfall variables}

The regional dataset identified in the previous section provides the rainfall time series used in this study to identify signals of possible climate changes; in particular, some time series are used as they come from the dataset, with no need
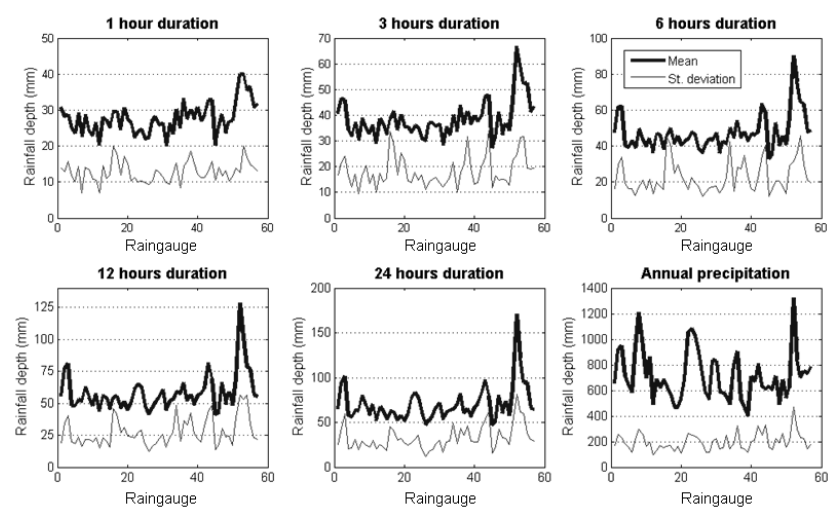

Fig. 2. Statistical characteristics in terms of mean value and standard deviation of the annual maximum rainfall for 1, 3, 6, 12 and $24 \mathrm{~h}$ duration and of the total annual precipitation for each rain gauge station.

of data preprocessing. This is the case of the annual maximum rainfall for fixed durations. In the case of other variables, the dataset has been opportunely preprocessed in order to derive the time series of interest for rainfall trend detection. In order to verify if and how daily rainfall events have changed over time in frequency and intensity, an intensitybased classification of daily rainfall has been adopted by fixing different intensity thresholds (in $\mathrm{mm} \mathrm{d}^{-1}$ ) defining each class. Six daily rainfall categories are first used following the same approach of Alpert et al. (2002), who classified rainfall intensity as power of 2 , starting from a value of $4 \mathrm{~mm} \mathrm{~d}^{-1}$ (upper limit of the first class) to a value of $128 \mathrm{~mm} \mathrm{~d}^{-1}$ (lower limit of the last class) (classification A, Table 1). Classification includes the following: light, light-moderate, moderate-heavy, heavy,heavy-torrential and torrential precipitation classes. The choice of such a classification allows one to analyze several rainfall categories and compare the results with those of other studies (Alpert et al., 2002). However, due to the moderate characteristics of rainfall intensity in Sicily, this study also considers a further, more simplified classification based on three rainfall categories: light precipitation $\left(0.1 / 4 \mathrm{~mm} \mathrm{~d}^{-1}\right)$, moderate precipitation $\left(4 / 20 \mathrm{~mm} \mathrm{~d}^{-1}\right)$ and heavy-torrential precipitation $\left(\geq 20 \mathrm{~mm} \mathrm{~d}^{-1}\right)$ (classification B, Table 1).

The analysis has been carried out by assessing both the annual percentage of rainfall events falling within each class (annual occurrences, \%) and the annual contribution of each class to the total annual volume (annual volume, \%). This allows one to evaluate the presence of trends by focusing on each rainfall category.

From the daily rainfall series recorded at the sites across Sicily, other rainfall characteristics have been derived at both the annual and the seasonal scale. In particular, the average rainfall intensity, the average rainfall frequency and the total precipitation have been considered. The average rainfall intensity was calculated as the mean depth of the rainfall 
events, corresponding to the mean daily depth in days when precipitation occurs, named $\alpha$ and measured in $\mathrm{mm} /$ rainy days; the average rainfall frequency was derived as the inverse of the mean interarrival times between subsequent events, named $\lambda$ and measured in rainy days/days; the total precipitation is the rainfall depth over the considered period. At the seasonal scale, two seasons are considered within the year based on the typical precipitation regime of Sicily and Mediterranean areas: the dry season (from April to September) and the wet season (the remaining part of the year).

To summarize, the Mann-Kendall trend test has been then applied to the following annual time series: (1) extreme rainfall data (maximum rainfalls at 1, 3, 6, 12 and $24 \mathrm{~h}$ duration); (2) number of occurrences of daily rainfall events within the rainfall categories identified in classification $\mathrm{A}$ and classification B; (3) contribution of each rainfall category identified in classification A and classification B to the total annual precipitation volume; (4) average rainfall intensity, $\alpha$; (5) average rainfall frequency, $\lambda$; and (6) total rainfall. Variables at points (2) and (3) have been analyzed at both the local scale (at site) and the regional scale by averaging the values over the stations through a simple mean, while variables at points (4), (5) and (6) have been screened at both the annual and the seasonal scale. For variables at point (1), the confidence level of Mann-Kendall test has been set at $95 \%$, (i.e., significance level $\left.\alpha_{\text {sig }}=0.05\right)$ and at $90 \%\left(\alpha_{\text {sig }}=0.1\right)$, while for remaining variables only $\alpha_{\text {sig }}=0.05$ has been considered.

\section{Analysis and results}

\subsection{Extreme rainfall analysis}

Application of the Mann-Kendall test to the five annual maximum series for different durations may indicate possible duration-dependent trend existence in the extreme rainfall events over the region. The results are globally shown in Fig. 3 on the left, which provides the percentage of stations exhibiting a positive trend (red), a negative trend (green) or no trend (gray) for each selected duration and $\alpha_{\text {sig }}=0.05$. Although most of the stations have shown no trend in their time series for all the considered durations, a significant positive trend occurs mostly for the shortest duration $(1 \mathrm{~h})$, detected at about the $14 \%$ of rain gauge stations. For the durations of 3,6 and $12 \mathrm{~h}$, a positive trend has been detected at about the $4-6 \%$ of the stations, while for the $24 \mathrm{~h}$ duration no station has exhibited a positive trend. A general behavior might be derived from the above results, according to which the longer the duration, the lower the percentage of stations with a positive trend. This finding is better highlighted by the results obtained for $\alpha_{\text {sig }}=0.1$ shown on the right of Fig. 3; in this case, about the $25 \%$ of rain gauge stations have exhibited a positive significant for the shortest duration $(1 \mathrm{~h})$, and this percentage gradually decreases with the rainfall duration up to a percentage of $4 \%$ for the $24 \mathrm{~h}$

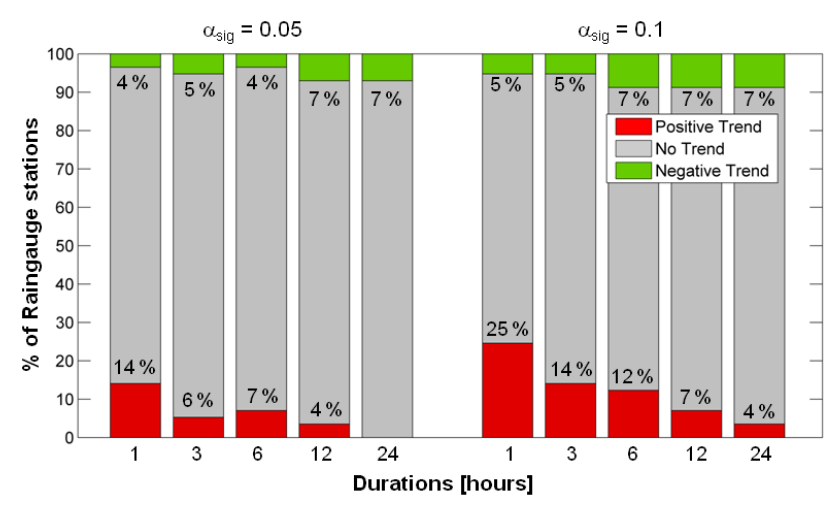

Fig. 3. Percentage of rain gauges showing a positive (red), negative (green) and a no trend (gray) in the annual maxima historical time series for 1, 3, 6, 12 and $24 \mathrm{~h}$, and for significance level $\alpha_{\text {sig }}=0.05$ (left) and $\alpha_{\text {sig }}=0.1$ (right).

duration. This result, extrapolated towards sub-hourly durations, suggests that there could be an increase in extreme events relative to such durations, similar to the cases studied by De Toffol et al. (2009) and Adamowski et al. (2010), which demonstrated the existence of trends in very short durations. On the other hand, the percentage of stations showing a negative trend exhibits values ranging from 4 to $5 \%$, in the case of short durations, to $7 \%$, in the case of longer durations. Moreover, the percentage correlation with the duration is less pronounced than in the case of positive trend analysis, rather showing almost a constant behavior with duration. Even increasing the significance level, i.e., for $\alpha_{\text {sig }}=0.1$, the results confirm the independence of the trend on the duration, maintaining about the same percentage values; indeed, only for $d$ equal to 1 and $6 \mathrm{~h}$ are there a few more stations exhibiting negative trend than in the case of $\alpha_{\text {sig }}=0.05$ (respectively $1 \%$ and $3 \%$ more stations), suggesting that the results of negative trends are not sensible to the chosen significance level but that they are sufficiently significant. Finally, since the percentage of negative trend is almost constant, while the one of the positive trends decreases with the duration, it follows that the percentage of rain gauge stations not showing a significant trend increase with the duration; in the case of $\alpha_{\text {sig }}=0.05$, values range from $82 \%$ ( $1 \mathrm{~h}$ ) to $93 \%$ $(24 \mathrm{~h})$, while for $\alpha_{\text {sig }}=0.1$ the percentages are lower, ranging from $70 \%(1 \mathrm{~h})$ to $88 \%(24 \mathrm{~h})$. Similar results were observed in the work of Bonaccorso et al. (2005), in which an increasing trend was detected only for maxima precipitation at $d=1 \mathrm{~h}$, while decreasing trends were detected at longer durations, with increasing percentages moving from 3 to $24 \mathrm{~h}$. Since the size of the dataset (number of rain gauges) in the present study is much higher than that used by Bonaccorso et al. (2005), as well as much more distributed over the region (57 vs. 16 mostly placed in eastern Sicily), results obtained here can be considered as a sound and consistent confirmation of the previous results. 
Table 1. Daily rainfall categories according to Alpert et al. (2002) (classification A) and proposed in this work (classification B).

\begin{tabular}{|c|c|c|c|c|c|}
\hline \multicolumn{3}{|c|}{ Classification A } & \multicolumn{3}{|c|}{ Classification B } \\
\hline Class & $\begin{array}{l}\text { Intensity } \\
{\left[\mathrm{mm} \mathrm{d}^{-1}\right]}\end{array}$ & Description & Class & $\begin{array}{l}\text { Intensity } \\
{\left[\mathrm{mm} \mathrm{d}^{-1}\right]}\end{array}$ & Description \\
\hline 1 & $0.1 \leq I<4$ & Light & 1 & $0.1 \leq I<4$ & Light \\
\hline 2 & $4 \leq I<16$ & Light-moderate & 2 & $4 \leq I<20$ & Moderate \\
\hline 3 & $16 \leq I<32$ & Moderate-heavy & 3 & $I \geq 20$ & Heavy-torrential \\
\hline 4 & $32 \leq I<64$ & Heavy & & & \\
\hline 5 & $64 \leq I<128$ & Heavy-torrential & & & \\
\hline 6 & $I \geq 128$ & Torrential & & & \\
\hline
\end{tabular}

Spatial distribution of the Mann-Kendall test outcomes for the five considered durations is shown in Fig. 4 for only $\alpha_{\text {sig }}=0.05$. Dots indicate rain gauge sites, while the presence of a significant positive or negative trend at each station is denoted by a red or a green circle, respectively, whose size is proportional to the trend magnitude $(\beta)$. The top left panel of Fig. 4 localizes the $14 \%$ of the rain gauges that have shown a positive trend for annual maximum rainfall with $1 \mathrm{~h}$ duration (see Fig. 3). Almost all of these are located in coastal areas, many in the western part of the region and only one in southern Sicily. The panels relative to the analyses for durations of 12 and $24 \mathrm{~h}$ show how the most relevant negative trends have been detected in time series from stations located in the inland western part of the region.

Again, results suggest that the increase in short-duration precipitation can be assumed as a general behavior over the region, especially along the coastline. Moving from the first panel $(1 \mathrm{~h})$ to the last $(24 \mathrm{~h})$, the number of stations exhibiting a positive trend gradually decreases. At the same time different stations showing a negative trend appear, whose magnitude increase with the duration. However, no well-defined spatial pattern seems to be outlined by these results. Similar results have been found out for $\alpha_{\text {sig }}=0.1$, here omitted for sake of simplicity.

The increase of rainfall of short durations has important implications in the design and verification of urban drainage systems, as well as of hydrological basin response, especially for the small catchments typically present in Sicily, where the concentration time is often lower than $1 \mathrm{~h}$; the increase of extreme events leads to an increase of the basin streamflow and the hydrograph peak, with important consequences on the dynamics of flood phenomena and their relative hazard.

\subsection{Analysis of rainfall categories}

The analysis here discussed considers the annual occurrences of daily rainfall events within the rainfall categories identified in classification $\mathrm{A}$ and classification $\mathrm{B}$, and annual contribution of each rainfall categories to the total annual precipitation volume, at both regional and local scale. This analysis

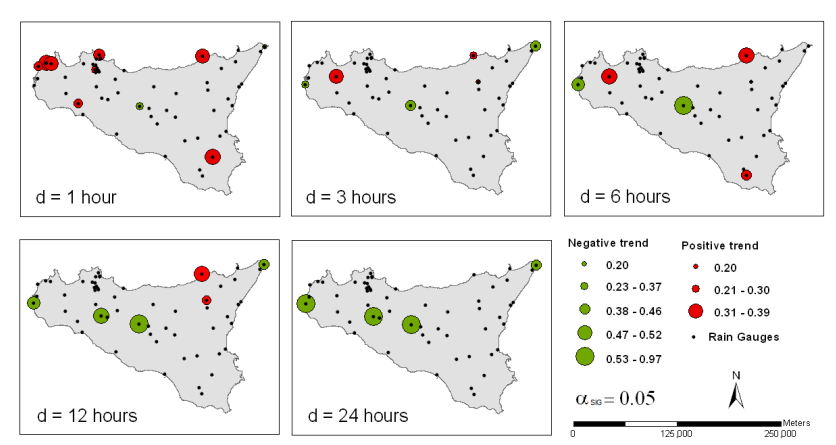

Fig. 4. Spatial distribution of the analyzed rain gauges and trend sign and magnitude of annual maxima time series exhibiting a significant trend for the five rainfall durations.

aims to verify whether frequency of torrential events and light events has either increased or decreased.

Regional results are summarized in Fig. 5 for both classification A (panel a and b) and classification B (panel $\mathrm{c}$ and d), and for both of the two variables.

Each point of Fig. 5 represents the average over the region of the values of the two analyzed variables obtained on-site, calculated as a simple mean of those values (percentage of annual occurrences of rainfall events within each class and percentage of annual contribution of each class to the annual volume). Observations from Fig. 5a suggest, as expected, that most of the annual occurrences belong to the class of light precipitation (class 1), with an average frequency of $60 \%$ over the entire time window. In general, the higher the intensity (i.e., rainfall category), the lower the frequency of occurrence. In fact, class 2 has an average frequency of $30 \%$ and class 3 of about $10 \%$. Average frequency of the last three classes is less than $5 \%$, and as such daily rainfall events with depth higher than $32 \mathrm{~mm}$ can be reasonably considered as rare. The Mann-Kendall test, which has been applied to each time series, has demonstrated that no trend exists for such series, denoting a stationary behavior.

The rainfall contributions of each class to the total annual volume are shown in Fig. 5b. Class 2 is the most significant in terms of rainfall contribution to the total volume (an average 

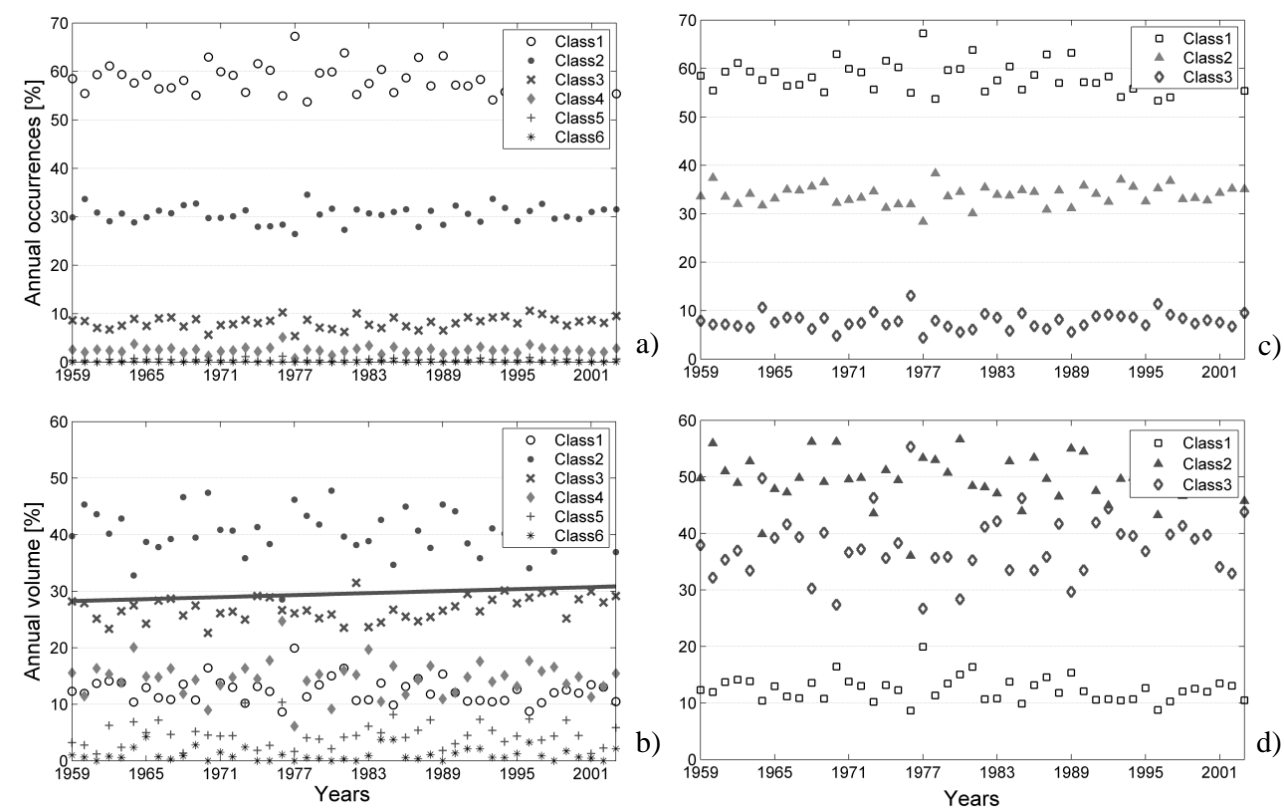

Fig. 5. Daily rainfall analysis: rainfall contribution to annual occurrences from each class (a and c) and to the total annual volume from each class (b and $\mathbf{d}$ ) as regional average over all the stations, based on classification A (a and $\mathbf{b})$ and classification B (c and $\mathbf{d})$. The presence of a straight line indicates trend existence.

of $40 \%$ ). Class 3 is the only class exhibiting a statistically significant positive trend, suggesting that the mean annual number of events with intensity belonging to this class (16$32 \mathrm{~mm} \mathrm{~d}^{-1}$ ) tends to increase. Classes 1, 4, 5 and 6 do not show significant trends, with a weak relative contribution to the annual total volume given their low frequency.

Similar observations come out from the analysis of rainfall events according to classification B, depicted in Fig. 5c and d. In this different classification, the class of low-intensity events is the same used in classification 1 (class 1) and the second class (moderate) includes class 2 and part of class 3 of classification A, while the third class (heavy-torrential events) includes the remaining part of class 3 and the entirety of classes 4, 5 and 6 of classification A. As a consequence, pattern in terms of annual occurrence is the same described before, up to the classes 4, 5 and 6 , whose contributions are redistributed between class 2 and 3 of classification B. Despite this, redistribution implies a different behavior in terms of contribution to the total annual volume, and also in this case no significant trend has been detected.

These results seem to be in disagreement with the findings of Alpert et al. (2002)'s work, who conducted a similar procedure to the Italy as a whole, obtaining increasing trends for heavy-torrential categories and decreasing trends for the weaker categories. However, it is important to highlight how the adopted regional analysis, based on averaged values among the different rain gauges, probably hides any local tendency, suggesting that, most probably, in the work of Alpert et al. (2002), regions other than Sicily had shown the most significant trends.
For this reason, changes over time of the two considered stochastic variables have been also investigated at a local level, i.e., for each station. For sake of simplicity, only the results obtained for classification B are here reported (Fig. 6), given that the analysis for classification A has provided similar results. In terms of annual occurrences (Fig. 6, first row), a number of stations, mainly located in northwestern Sicily, exhibit a negative significant trend, especially for class 1: this means that there is a decreasing tendency in the number of events that are primarily light precipitation. Only two stations, far from each other, have shown a positive trend for low-intensity events. However, moving from class 1 to class 3 , several stations distributed over the region exhibit a positive trend, suggesting an increasing tendency in the number of heavy-torrential precipitation events, in accord with Alpert et al. (2002).

In terms of annual volume (Fig. 6, second row), the contribution of light precipitation (class 1) tends to decrease in some stations (negative trend) and to increase in others (positive trend). Again, northwestern Sicily is the area of most interest for this change. Moderate precipitation (class 2), instead, shows a decrease in contribution to the total annual volume. Lastly, heavy-torrential precipitation events tend to increase their contribution to the annual volume in most of the stations showing a statistically significant trend. This could be explained as a consequence of the increase in heavy-torrential occurrences. 


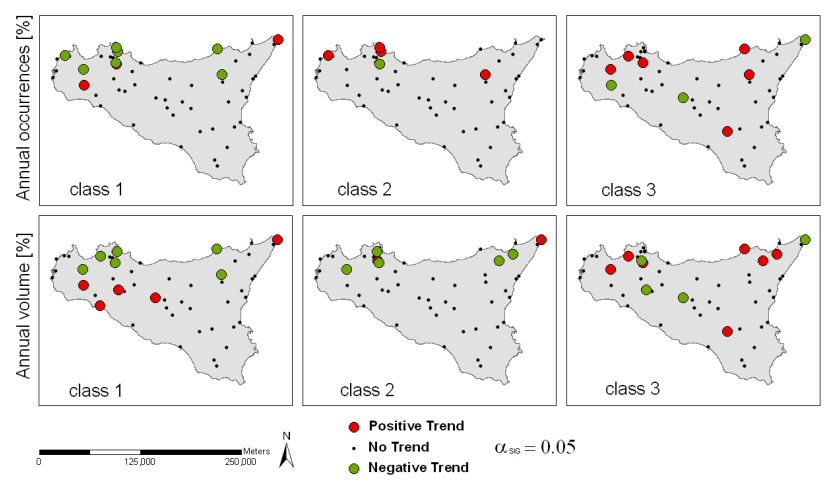

Fig. 6. Daily rainfall analysis: results from single rain gauge station for the two considered stochastic variables (contribution to annual occurrences and rainfall contribution to the total annual volume from each class) and classification B. Here only the presence, either positive (red circles) or negative (green circles), and the absence of trend (black points) are depicted.

\subsection{Analysis of rainfall properties}

In this section, the trend analysis of daily rainfall properties are described in terms of average rainfall intensity and frequency in order to verify the existence of any potential change in such properties. The main results of the Mann-Kendall test application to the different time series are synthesized in Fig. 7, where the percentage of stations showing statistically significant trends is reported at annual (YEAR) and seasonal (DRY and WET) time scale. The results of the average rainfall intensity at the annual $\left(\alpha_{\text {YEAR }}\right)$, wet $\left(\alpha_{\mathrm{WET}}\right)$ and dry $\left(\alpha_{\mathrm{DRY}}\right)$ period are reported in the first row of Fig. 7. Results show a decreasing trend of $\alpha_{\text {YEAR }}$ in $75 \%$ of the considered stations, while the remaining $25 \%$ show no trend. Seasonal results are very similar to the annual ones: in the wet season, which consists of winter and fall months, the percentage of stations showing negative trends is almost the same (i.e., $72 \%$ ), while it slightly decreases in the dry period (i.e., $65 \%$ ). An important result depicted in the first row of Fig. 7 is thus that most of the screened rain gauge stations over the region have manifested a decreasing tendency in the average intensity of the rainfall events at both the annual and the seasonal time scale, while none of them has shown increasing trends.

The results of the analysis on the average rainfall frequency are shown in the second row of Fig. 7 ( $\lambda_{\text {YEAR }}, \lambda_{\text {WET }}$ and $\lambda_{\text {DRY }}$ ). At the annual scale the most important outcome is that rainfall frequency does not show trends for $63 \%$ of the considered stations. A considerable percentage, namely $30 \%$, show a negative trend, which means rarer events, while in $7 \%$ of stations rainfall events are more frequent. These percentages remain more or less constant in the wet season analysis. During the dry period, generally characterized by a lower rainfall events frequency, the percentage of stations showing no trend increases to $75 \%$, while the remaining

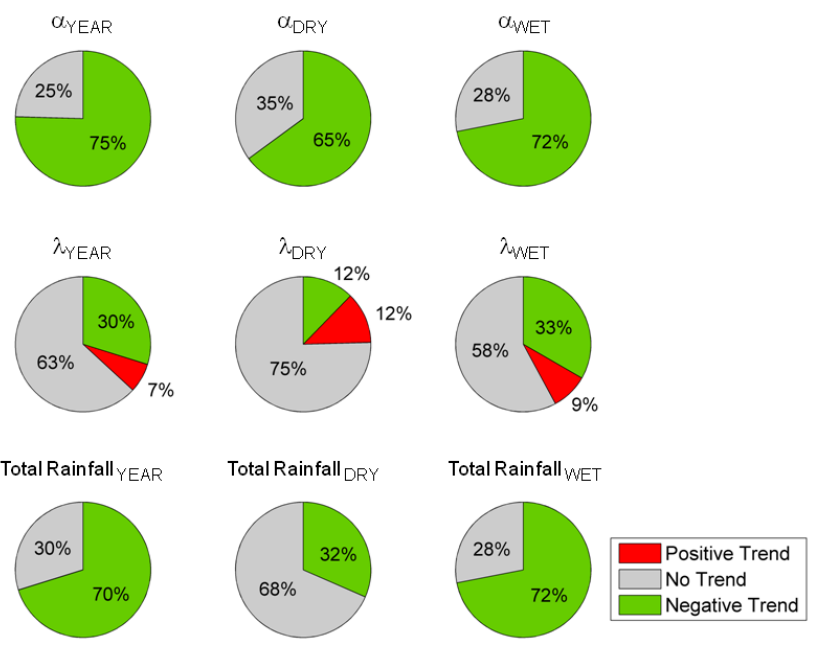

Fig. 7. Daily rainfall analysis: percentage of stations showing negative, positive or no significant trend in average rainfall intensity (first row), frequency (second row) and in total rainfall. Columns present annual (first), dry (second) and wet (third) period results.

percentage of stations showing trend is equally distributed between stations where the rainfall events tend to be rarer (negative trend) and more frequent (positive trend).

The aforementioned rainfall characteristics have also been combined and analyzed in order to provide a comprehensive view of water availability at the annual and the seasonal time scale. For a given period, the product of the average intensity, the average frequency and the duration of the same period provides the average total amount of rainfall for that period (Total Rainfall YEAR, Total Rainfall ${ }_{\mathrm{WET}}$ and Total Rainfall $_{D R Y}$ ). The Mann-Kendall test application on the average total rainfall (third row of Fig. 7) has shown how, at the annual time scale, $70 \%$ of the considered stations show a negative trend, coherent with the outcomes of Cannarozzo et al. (2006). Water availability in Sicily has decreased in the last century because of a generalized reduction of the average rainfall intensity, as is shown in the first row of Fig. 7. In some cases this reduction is dramatic because it is associated with a frequency reduction, while in others it is mitigated by a frequency increase.

The total rainfall in the wet period follows the annual behavior, with $72 \%$ of stations showing negative trends and $28 \%$ showing no trends. In fact, since the majority of the annual rainfall is concentrated in this season, it is expected that this tendency is reflected at the annual scale. This season is crucial for Mediterranean ecosystems because resupplies soil water content, which in turn represents a fundamental water reserve for facing the subsequent drier season, usually coincident with the growing season for vegetation. At the same time the water input arising from winter and fall months is decisive for storage systems, which are required in order to store water resources for future use. 


\section{Conclusions}

According to the most recent climate predictions, Mediterranean ecosystems will probably face a radical modification of the climatic conditions in the near future due to global warming, mainly related to the greenhouse effect.

This work has investigated potential modifications in the rainfall regime of Sicily, attempting to detect through historical records any potential changes or trends in various rainfall features, and considering annual extreme events for different durations, daily rainfall series and corresponding properties at both the annual and the seasonal scale. A dense network of rain gauge stations distributed over the region has provided an important database of long rainfall series. The historical rainfall data, opportunely processed in order to extrapolate the main average features, have been analyzed through use of the nonparametric Mann Kendall test with a significance level of 0.05 , and in a case also with significance level of 0.1 . The results have provided an overview of potential trends identified in some characteristics of the rainfall at the regional and local level.

Analysis of annual maximum rainfalls at 1, 3, 6, 12 and $24 \mathrm{~h}$ have reveled a significant increase in precipitation of short duration, especially for $1 \mathrm{~h}$ rainfall, in agreement with many scientific works (Adamowski et al., 2010; Bonaccorso et al., 2005; De Toffol et al., 2009; Burn et al., 2011). Conversely, the percentage of stations showing a positive trend tends to decrease when increasing durations are considered. This tendency has been clearly highlighted by the results at $90 \%$ confidence level. No clear spatial pattern emerged from this analysis, even if coastal areas seem to be much more affected by positive trends than internal areas. As the rainfall duration increases, the percentage of stations with negative trends becomes slightly more relevant, with a decrease of rainfall volume for longer events, in agreement with results of Bonaccorso et al. (2005).

These results lead to important implications in flood risk management for many small Sicilian catchments, whose concentration times are often lower than $1 \mathrm{~h}$. In fact, the increase of extreme rainfall in small basins implies an immediate increase of the basin streamflow and the hydrograph peak, which in turn lead to important consequences on the flood phenomena and the connected flood risk. It is clear how all these consequences will affect all the hydrological applications that make use of those variables, such as the design of water engineering structures, with the effect of cost increase in the case of new structures, and increased risk in the case of existing structures.

Daily rainfall time series have been screened firstly using two different threshold-based classifications and analyzing the annual occurrences of rainfall events with intensity within each class and the annual contribution of each class to the total annual precipitation. Results at the sites have shown an increase in the number of events per year that can be classified as heavy-torrential precipitation in spite of a reduction of the annual occurrence of light rainfall events. Moreover there is an increasing relative contribution of such heavy precipitation events to the total annual volume. When the results are averaged at regional scale, the strength of local outcomes vanishes, showing no significant trend.

A high percentage of the Sicilian rain gauge stations have shown a significant negative trend in the total annual precipitation, mainly due to a reduction in the seasonal rainfall during the wet period (fall and winter). A similar percentage of stations have shown how all the rainfall events (during both the wet and dry season) tend to be less intense, while very few stations are characterized by significant changes in the frequency of rainfall events.

One of the immediate consequences of the rainfall reduction may be an increase in the vegetation water stress (Pumo et al., 2010). In the coming years, all of this could cause a significant modification of vegetation patterns characteristic of Mediterranean areas. In particular, the water uptake dynamics of shallow-rooted species quickly respond to the water input changes; for example, for grasses species, it follows that the state of their health is strongly related to the frequency of rainfall events regardless of the amount of rainfall in the previous period. On the other hand, water stored in the soil during the winter period is often an important water resource for the subsequent dry period, especially for woody species, which use the winter water stored in the deeper soil layers. It follows that, if the rainfall reduction is concentrated during the wet season, as emerges from this study, shallow-rooted species could have some advantages over the deep-rooted species.

Acknowledgements. The work has been partially funded by the Flagship Project RITMARE - Italian Sea Research - coordinated by the Italian National Research Council and funded by the Italian Ministry of Education, University and Research within the National Research Program 2011-2013; and by the project MEDIWAT - Sustainable management of environmental issues related to water stress in Mediterranean islands - financed by the EU in the framework of the MED Programme.

Edited by: Z. Bargaoui

\section{References}

Adamowski, J., Adamowski, K., and Bougadis, J.: Influence of trend on short duration design storms, Water Resour. Manage., 24, 401-413, 2010.

Alpert, P., Ben-Gai, T., Baharad, A., Benjamini, Y., Yekutieli, D., Colacino, M., Diodato, L., Ramis, C., Homar, V., Romero, R., Michaelides, S., and Manes, A.: The paradoxical increase of Mediterranean extreme daily rainfall in spite of decrease in total values, Geophys. Res. Lett., 29, 1-31, doi:10.1029/2001GL013554, 2002. 
Aronica, G., Cannarozzo, M., and Noto, L.: Investigating the changes in extreme rainfall series recorded in an urbanised area, Water Sci. Technol., 45, 49-54, 2002.

Bonaccorso, B., Cancelliere, A., and Rossi, G.: Detecting trends of extreme rainfall series in Sicily, Adv. Geosci., 2, 7-11, doi:10.5194/adgeo-2-7-2005, 2005.

Brunetti, M., Buffoni, L., Maugeri, M., and Nanni, T.: Precipitation intensity trends in northern Italy, Int. J. Climatol., 20, 10171031, 2000.

Brunetti, M., Colacino, M., Maugeri, M., and Nanni, T.: Trends in the daily intensity of precipitation in Italy from 1951 to 1996, Int. J. Climatol., 21, 299-316, 2001.

Burn, D. H., Mansour, R., Zhang, K., and Whitfield, P. H.: Trends and Variability in Extreme Rainfall Events in British Columbia, Can. Water Resour. J., 36, 67-82, doi:10.4296/cwrj3601067, 2011.

Cannarozzo, M., Noto, L. V., and Viola, F.: Spatial distribution of rainfall trends in Sicily (1921-2000), Phys. Chem. Earth, 31, 1201-1211, 2006.

Dai, A., Trenberth, K. E., and Karl, T. R.: Global variations in droughts and wet spells: 1900-1995, Geophys. Res. Lett., 25, 3367-3370, 1998.

De Toffol, S., Laghari, A. N., and Rauch, W.: Are extreme rainfall intensities more frequent? Analysis of trends in rainfall patterns relevant to urban drainage systems, Water Sci. Technol., 59, 1769-1776, 2009.

Di Piazza, A., Conti, F. L., Noto, L. V., Viola, F., and La Loggia, G.: Comparative analysis of different techniques for spatial interpolation of rainfall data to create a serially complete monthly time series of precipitation for Sicily, Italy, Int. J. Appl. Earth Obs., 13, 396-408, 2011.

Giorgi, F. and Lionello, P.: Climate change projections for the Mediterranean region, Global Planet. Change, 63, 90-104, 2008.

Groisman, P. Y., Karl, T. R., Easterling, D. R., Knight, R. W., Jamason, P. F., Hennessy, K. J., Suppiah, R., Page, C. M., Wibig, J., Fortuniak, K., Razuvaev, V. N., Douglas, A., Forland, E., and Zhai, P. M.: Changes in the probability of heavy precipitation: Important indicators of climatic change, Climatic Change, 42, 243-283, 1999.

Hirsch, R. M., Slack, J. R., and Smith, R. A.: Techniques of trend analysis for monthly water-quality data, Water Resour. Res., 18, 107-121, 1982.

Houghton, J. T., Meira Filho, L. G., Callander, B. A., Harris, N., Kattenberg, A., and Maskell, K.: Climate Change 1995: The Science of Climate Change, in: Contribution of Working Group 1 to the Second Assessment Report of the Intergovernmental Panel on Climate Change, Cambridge University Press for the Intergovernmental Panel on Climate Change, Cambridge, New York, Port Chester, Melbourne, Sydney, 1-572, 1996.

Kendall, M. G.: Rank Correlation Methods, Hafner Publishing Company, New York, 1962.
Kunkel, K. E., Andsager, K., and Easterling, D. R.: Long-term trends in extreme precipitation events over the conterminous United States and Canada, J. Climate, 12, 2515-2527, 1999a.

Kunkel, K. E., Pielke Jr., R. A., and Changnon, S. A.: Temporal fluctuations in weather and climate extremes that cause economic and human health impacts: A review, B. Am. Meteorol. Soc., 80, 1077-1098, 1999b.

Lionello, P., Malanotte-Rizzoli, P., Boscolo, R., Alpert, P., Artale, V., Li, L., Luterbacher, J., May, W., Trigo, R., Tsimplis, M., Ulbrich, U., and Xoplaki, E.: The Mediterranean climate: An overview of the main characteristics and issues, Developments in Earth and Environmental Sciences, 4, 1-26, 2006.

Mann, H. B.: Non parametric tests again trend, Econometrica, 13, 245-259, 1945.

Mason, S. J., Waylen, P. R., Mimmack, G. M., Rajaratnam, B., and Harrison, J. M.: Changes in extreme rainfall events in South Africa, Climatic Change, 41, 249-257, 1999.

Osborn, T. J., Hulme, M., Jones, P. D., and Basnett, T. A.: Observed trends in the daily intensity of United Kingdom precipitation, Int. J. Climatol., 20, 347-364, 2000.

Plummer, N., Salinger, M. J., Nicholls, N., Suppiah, R., Hennessy, K. J., Leighton, R. M., Trewin, B., Page, C. M., and Lough, J. M.: Changes in climate extremes over the Australian region and New Zealand during the twentieth century, Climatic Change, 42, 183-202, 1999.

Pumo, D., Viola, F., and Noto, L. V.: Climate changes' effects on vegetation water stress in Mediterranean areas, Ecohydrology, 3, 166-176, 2010.

Trenberth, K. E., Jones, P. D., Ambenje, P., Bojariu, R., Easterling, D., Klein Tank, A., Parker, D., Rahimzadeh, F., Renwick, J. A., Rusticucci, M., Soden, B., and Zhai, P.: Observations: Surface and Atmospheric Climate Change, in: Climate Change 2007: The Physical Science Basis. Contribution of Working Group I to the Fourth Assessment Report of the Intergovernmental Panel on Climate Change, edited by: Solomon, S., Qin, D., Manning, M., Chen, Z., Marquis, M., Averyt, K. B., Tignor, M., and Miller, H. L., Cambridge University Press, Cambridge, UK and New York, NY, USA, 2007.

Ulbrich, U., May, W., Li, L., Lionello, P., Pinto, J. G., and Somot, S.: The Mediterranean climate change under global warming, in: Mediterranean Climate Variability and predictability, edited by: Lionello, P., Malanotte-Rizzoli, P., and Boscolo, R., Elsevier, Amsterdam, 398-415, 2006.

Villarini, G., Smith, J. A., Baeck, M. L., Vitolo, R., Stephenson, D. B., and Krajewski, W. F.: On the frequency of heavy rainfall for the Midwest of the United States, J. Hydrol., 400, 103-120, 2011.

Yue, S. and Wang, C. Y.: Applicability of prewhitening to eliminate the influence of serial correlation on the Mann-Kendall test, Water Resour. Res., 38, 1068, doi:10.1029/2001wr000861, 2002. 